\title{
Peace agreements without commitment th
}

\author{
Carmen Beviáa,*, Luis C. Corchón ${ }^{\mathrm{b}}$ \\ a Departament d'Economia i d'Història Econòmica and CODE, Universitat Autònoma de Barcelona, Spain \\ ${ }^{\mathrm{b}}$ Departamento de Economía, Universidad Carlos III, Spain
}

\section{A R T I C L E I N F O}

\section{Article history:}

Received 12 February 2009

Available online 12 October 2009

\section{JEL classification:}

C72

D74

\begin{abstract}
A B S T R A C T
In this paper we present a model of war between two rational and completely informed players. We show that in the absence of binding agreements war can be avoided in many cases by one player transferring money to the other player. In most cases, the "rich" country transfers part of its money to the "poor" country. But when the military proficiency of the "rich" country is sufficiently high the "poor" country stops the war by transferring part of its resources to the "rich" country. War cannot be avoided by transfers when inequality of resources is very large or the cost of war is sufficiently low.
\end{abstract}

\section{Introduction}

War has played an important role in human history. Social scientists have devoted a great deal of attention to show how rational and fully informed players can engage in war, e.g. Bueno de Mesquita (1981), O'Neill (1990), Hirshleifer (1991), Skaperdas (1992), Sánchez-Pagés (2006) and Jackson and Morelli (2007). This approach leaves out many relevant factors such as irrational or incompletely informed players, religion, politics, ethnicity, etc. But by focusing on such a stylized world, it captures the core of many conflicts, namely rational interest in some valuable resource. ${ }^{1}$

On the contrary, the question of which kind of agreements can prevent war-which is a wasteful way to settle conflictshas been relatively neglected. A difficulty here is how to explain the commitment of both parties to the agreed upon course of action. ${ }^{2}$ On the one hand, contracts between two sovereign states are, usually, not legally enforceable. ${ }^{3}$ On the other hand, reputation effects can only arise under incomplete information or in infinitely repeated games (Fearon, 1995, p. 409).

There is ample historical evidence of such agreements: Roman emperors used to buy peace with invaders, e.g., Alaric was paid 5000 pounds of gold, 30,000 pounds of silver plus other valuables in return for calling off the siege of Rome in 409 AD (Gibbons, 1776-1788, Chapter XXXI). Attila obtained 13,000 pounds of gold during the period 440-450 AD from the eastern provinces of the Roman empire to stop him from invading them (Keegan, 1994, p. 183). Both Alaric and Attila

\footnotetext{
We are grateful to C. Alós, B. Bueno de Mesquita, J. Conley, D. Cardona, M. Dahm, J. Eguia, R. Ferrer, K. Huang, P. Liangh, H. Llavador, A. Nakkas, D. Ong, C. Plott, M. Quinzii, J. Reingannum, S. Sánchez-Pagés, J. Silvestre, Q. Wen, A. Wolinsky, J. Weymark, G. Zudenkova, audiences in seminars at Vanderbilt University, Northwestern University, California University at Davis and California Institute of Technology, the associate editor and two anonymous referees for very helpful suggestions. The first author acknowledges financial support from SEJ2006-27589-E, ECO2008-04756, 2005SGR-00454, and Barcelona GSE research network. The second author acknowledges financial support from SEJ2005-06167/ECON.

* Corresponding author.

E-mail address: carmen.bevia@uab.es (C. Beviá).

1 The connection between war and games was already noticed by Clausewitz (1832, Chapter 1, end of paragraph 21): "War is akin to a card game".

2 When we refer to commitment we follow the terminology used by Jackson and Morelli (2007, p. 1359 and ff.) where the "commitment case" is defined as a situation "... where the countries can sign some (internationally) enforceable treaty so that they will not go to war conditional on the transfer". See pp. 1361 and ff. for "The No-Commitment Case" defined as “... situations where a country cannot commit to avoid a war if it receives transfers".

3 This is one of the differences between legal batles and wars: In the former, pre-trial agreements are enforceable and in the latter this is not necessarily the case.
} 
knew Rome very well. The first served in the Roman army and the second spent time in Rome as a hostage. The eastern Roman emperor Justinian and his Persian counterpart, Chosroes, negotiated a long series of agreements, some of which were upheld, e.g., the truce in $541 \mathrm{AD}$ in which the Persians agreed not to attack Byzantine territory for the next five years in return for 5000 pounds of gold (Evans, 1998). An "everlasting” peace agreement, though, lasted only for 10 years. Viking kings used to be "bought off" in tenth century England. They also received Normandy from the king of France in return for lifting the siege of Paris (Sykes, 2006, p. 263). Christian kingdoms used to extort the Moorish kingdoms in eleventh century Spain with tributes called Parias in return for peace, but two centuries earlier similar tributes were paid the other way around (Nelson, 1979). The Song empire appeased the Tangut and the Liao empires with gold, silk, brocade and tea (http://www.chinaknowledge.de/History/Song/song-event.html). Tribal wars in Africa were avoided by paying slaves as tribute (Nunn, 2007 p. 6), etc. ${ }^{4}$ In many cases, agreements took place among people who knew each other well and with whom similar agreements-not all of them upheld-were struck in the past. Thus, it would be convenient to have an explanation for such agreements that does not rely exclusively on reputation effects or binding agreements.

Consider the following mechanism. Before war is waged, the potentially attacked player (the "prey") gives some resources to the potentially attacking player (the "predator") with a double target: to compensate him for the expected spoils of war and to make him so rich that he is no longer interested in waging war. Why is this so? Because of two reasons: on the one hand, the prey is slimmer after the transfer so the expected revenue from attacking will be less than before; on the other hand the predator has more to lose after the transfer because he is now richer. What is not so clear is that the prey is better off, since in some cases peace is paid for so dearly that war might be preferable. The objective of this paper is to explore the possibility of such agreements in a simple model with two finitely-lived and fully informed players.

The game is played as follows: In the first stage transfers are made. In the second stage players decide simultaneously if they declare war or not. If one of them declares war, war occurs. In the third stage, if there is war, each player decides the war effort. In the last stage the outcome of the war is determined and the winner takes all. ${ }^{5}$ Thus our model is close to Clausewitz's (1832) concept of absolute war. ${ }^{6}$

Our extensive form is not the only possibility but it is one in which the different decisions (war or peace, how much effort should be allocated to war, etc.) are separated in a neat way. We remark that our game does not allow for surprise attacks or for the possibility that once war efforts are chosen, peace can be achieved and the surplus divided. Let us consider these points in turn. Firstly, if a surprise attack wins the war, transfers are useless. But if war is not won with certainty by the surprise attack, transfers may still stop war (see our discussion of this point in Section 7). Secondly, once the armies are in place, we assume that war is unavoidable. For instance we might assume that sooner or later a random event will ignite war. A more general model in which once armies are built, war occurs with some probability (chosen by nature) would be an interesting extension of our work. Another possibility would be to consider mixed strategies, see Jackson and Morelli (2009).

We assume that the probability of winning war is a function of war efforts and two parameters: the (relative) military proficiency of player 1 and the responsiveness of the probability of winning war to war efforts. The latter is an inverse measure of the role of chance in war. For simplicity, we assume that a fixed proportion of war efforts can be recovered by the winner, so a fixed proportion of resources are lost in the war. Players are endowed with a resource that can be devoted to war effort or consumed. The resources of player 1 are larger than those of player 2 so the first (resp. second) player will be called the rich (resp. poor) player. Thus in our model there are four parameters: military proficiency, the role of chance in war, the (marginal) cost of war and the inequality of resources between players.

We start analyzing in Section 3 the "canonical" case where both players are equally proficient and the probability of winning the war is proportional to war efforts. In this case, the unique source of asymmetry among players is derived from the differences in resources. In absence of transfers, only the poor player has incentives to attack when inequality of resources is large and the marginal cost of war is not small. This occurs when the poor player uses all his resources in the war but the rich player does not (we say that the poor player is constrained but the rich player is unconstrained). The role of inequality of resources is clear: The poor player attacks in the hope of becoming rich. ${ }^{7}$ However, the effect of the marginal cost of war is contrary to what intuition suggests. A high cost of war may yield incentives to the poor player to attack since the resources used in war by the rich player are decreasing with the cost of the war. Thus, when this cost is high, the chances for the poor player to win the war are greater than when this cost is small. We show that in this case transfers avoid war unless inequality of resources is very large. The transfer from the rich to the poor country reduces resource inequality and induces peaceful behavior in the poor country. ${ }^{8}$ In any other case, peace is an equilibrium without transfers: If both players are unconstrained, war entails a small expected gain and a large loss of resources because in this

\footnotetext{
4 There are well-known cases where the policy of appeasement by means of transfers failed, e.g. the concessions of France and Great Britain to Adolf Hitler in the 1930's.

5 Bueno de Mesquita et al. (2003, p. 417) consider three outcomes following the defeat of a nation: confiscation of resources, installation of a puppet king and alteration of the institutions in the defeated country. Here we only consider the first alternative.

6 See Smith and Stam (2004) for a model of war more akin to Clausewitz's limited wars.

7 This provides an explanation of the uneven contenders paradox, raised by Clausewitz (1832), where a weak country initiates war, even though it has a small probability of winning the war. In the words of Adam Smith (1776, p. 659) "An industrious, and upon that account a wealthy nation, is of all nations the most likely to be attacked".

8 An implication of this is that it may be not a good idea to make a poor country even poorer because this may make war unstoppable.
} 
case the marginal cost of war is larger than 0.5. If both agents are constrained, war entails too much destruction because both players commit all their resources to the conflict and since the probability of winning is proportional to war efforts, in the most favorable case (zero marginal cost of war) they can only expect to gain exactly what they had before the war.

In Section 4, we consider the case where the probability of winning is not proportional to war efforts. When this probability is less responsive to war efforts to what was assumed in Section 3, the poor player has extra incentives to start a war because his chances of winning are now larger. Consequently, war may occur when both players are unconstrained or when both are constrained: In the limit, when war is just a fair lottery, war occurs even when the difference in resources is arbitrarily small. We show that in both cases, if inequality of resources is small, and the cost of war is not very small, transfers from the rich to the poor country avoid war. A transfer acts as a costless lottery that leaves both players better off. But when the probability of winning is more responsive to war expenses than we assumed in Section 3, the rich player has incentives to attack and if the cost of war is not very large, there are no transfers that avoid war.

In Section 5 we analyze the case where the rich country has an advantage in military proficiency. This advantage gives incentives to the rich player to attack in the absence of transfers, as in Bueno de Mesquita (1981, pp. 129 and 155). For this to occur its military proficiency should be high, the resources of the poor cannot be too small (so the potential loot is large) and the marginal cost of war has to be small (so the winner can recoup a sizeable part of war efforts). A large inequality protects the poor player from an attack by the rich player, since this player has little to gain. Transfers from the poor to the rich avoid war when the resources of the poor are sufficiently large.

Finally, we present a two period extension of the previous model where players receive a per period endowment and war efforts are bound by the per period endowment. We show that our main conclusions hold in this framework.

Summing up, we find that the transfer mechanism avoids war in a large number of cases showing that peaceful agreements may be reached in absence of commitment. This agrees with the observation of Morrow (2008) that "interstate war is very rare" and that "most disputes are resolved without escalating to war" (Morrow, 2008, pp. 11-13).

\section{Relationship with the literature}

Hirshleifer (1991), proposed a model where poor players often improve their position relative to rich ones. He called this the Paradox of Power. This is close to our observation that a high cost of war may yield incentives to the poor player to attack. But our models are different. Firstly Hirshleifer does not study the incentives to declare war; he just assumes that there is war. Secondly, in his model there is production and the marginal cost of war is one. Thirdly, he does not discuss the role of transfers in bringing peace.

Bueno de Mesquita and Lalman (1992) consider a sequential perfect information game where countries make demands on each other. They may grant the demands, challenge the demands or negotiate (with commitment). Under complete information when domestic factors (such as the ideology of the supporting coalition) do not play any role, war never arises in equilibrium (they call this case "Realpolitik"). This is because players either negotiate or remain at the status quo. However, when domestic factors play a role, war is possible.

Powell (1996) analyzed a dynamic model where "a state that is declining in power is unsure of the aims of a rising state. If those aims are limited, then the declining state prefers to appease the rising state's demands rather than go to war to oppose them" (p. 749). This appeasement takes the form of "salami tactics" where little concessions are made over time. Under complete information the policy of appeasement always brings peace (p. 755). There are several differences between our models: Ours is a model of a "decisive battle", not of a series of small conflicts. In addition, in his model the aggressor is exogenously chosen to be the rising state.

Bueno de Mesquita et al. (2003) consider a model where leaders have to obtain the support of a winning coalition in order to fight a war. After the war is fought "the members of the winning coalition... decide whether to retain their leader or to defect to a domestic political rival" (p. 265). Their model is somewhat similar to ours: war is modeled as a costly lottery and the probability that a country wins the war is increasing in the effort of leaders. However, the cost of war is fixed (pp. 227-228) and they do not consider the possibility of making transfers that may stop war.

Ponsatí (2004) studies bilateral conflicts that affect the welfare of a third party. The conflict takes the form of a war of attrition, and intervention is modeled as the possibility that the stakeholder aids the agreement with transfers to the contenders. In this case, the source of money is external to the conflict.

Jackson and Morelli (2007) study how the decisions to go to war depend on the political bias of decision makers. Political bias refers to the discrepancy between the interests of decision makers and citizens. They do not distinguish between war effort and resources. This can be interpreted in terms of our model by saying that they focus on the case where both decision makers are constrained. The main focus of this paper is the case where both parties can commit but they obtain some results on the non commitment case. Thus, if the decision makers are unbiased, two countries may decide to go to war depending on the responsiveness of the probability of winning the war to the difference in resources. This is very close to our Proposition 4, see also the discussion immediately after this result. Also, their Proposition 4 says that "if the probability of winning is proportional to relative wealths... two countries will never go to war if they can make transfers to each other (even without commitment)". The reason is that if the winning probabilities are proportional, no country wants to go to war in the absence of transfers, which is our Proposition 1. Thus, our paper extends their findings to the cases where war effort and resources are different for, at least, one decision maker. 
Finally, the issue of non-commitment has been used to explain war in a dynamic setting: In Garfinkel and Skaperdas (2000) because "peaceful settlement involves not only sharing the pie available today but also foregoing the possibility, brought about by war, of gaining a permanent advantage over one's opponent into the future" (p. 793). In Bester and Konrad (2005) because "contracts that yield an outcome that is Pareto superior to war require commitment about future resources or future decisions and cannot be enforced" (p. 212), see also the survey by Garfinkel and Skaperdas (2007), Section 5.2 and the references therein. A related point was made by Acemoglu (2003) in a political economy set-up "parties holding political power cannot make commitments to bind their future actions because there is no outside agency with the coercive capacity to enforce such arrangements". The use of transfers in games of conflict where the future use of this transfer is not contractible has been analyzed by Rajan and Zingales (2000). They apply their model to military conflicts and conclude that "our model provides a reason why military truces or cease-fires are not more frequent" (Section 5.1). This conclusion runs counter to our analysis in which, in many cases, transfers provide incentives to a peaceful outcome.

The rest of the paper goes as follows. We present our model in Section 2. In Sections 3, 4 and 5, we analyze the incentives for both players to go to war and when war can be avoided by transfers. In Section 6 we study the two period model. Finally, Section 7 concludes the paper and suggests some avenues for further research. All the proofs are gathered in Appendix A.

\section{The model}

There are two players with resources $V_{1}$ and $V_{2}$. W.l.o.g. we will assume that $V_{1}>V_{2}$. They play the following game.

In the first stage, each player may transfer part of his resources to the other player. ${ }^{9}$

In the second stage, each player decides whether to declare war on the other player or not. If a player declares war, war occurs. If both abstain from declaring war, peace results.

In the third stage, if there is peace, the game ends. Payoff to player $i$ is his resource $V_{i}, i=1,2$, plus the net transfer received in the first stage. If there is a war, each player commits part of his resources to the war effort, denoted by $e_{i}$, $i=1,2$. It is assumed that there is no outside credit and therefore no player can use in the war more than his available resources.

In the fourth stage, war is waged. The outcome is partially determined by nature and partially determined by war efforts. ${ }^{10}$ Thus in our model, the wealth of a nation does not translate automatically into military capabilities as in Bueno de Mesquita (1981, p. 102) and Jackson and Morelli (2007).

If $p_{i}$ is the probability that player $i=1,2$ wins the war, we assume that

$$
\begin{aligned}
& p_{1}=\frac{\lambda e_{1}^{\gamma}}{\lambda e_{1}^{\gamma}+e_{2}^{\gamma}} \text { and } \quad p_{2}=\frac{e_{2}^{\gamma}}{\lambda e_{1}^{\gamma}+e_{2}^{\gamma}}, \quad \text { if } \lambda e_{1}^{\gamma}+e_{2}^{\gamma}>0, \\
& p_{1}=p_{2}=\frac{1}{2}, \quad \text { if } \lambda e_{1}^{\gamma}+e_{2}^{\gamma}=0, \\
& \lambda \in(0, \infty), \quad 0 \leqslant \gamma \leqslant 1 .
\end{aligned}
$$

The functions in (2.1) are called contest success functions (CSF). The parameter $\lambda$ is a measure of the war skills of player 1. When $\lambda=1$, we will say that the CSF are symmetric. The parameter $\gamma$ measures the sensitivity of the probability of winning war to the efforts. When $\gamma=0$, the outcome of war is purely random. When $\gamma=1$, we will say that the CSF are proportional.

A motivation for this functional form is that it seems reasonable to require that the CSF is homogeneous of degree zero, so winning probabilities do not depend on how resources are measured (pounds or francs, number or thousands of soldiers, etc.). Clark and Riis (1998), following Skaperdas (1996), have shown that under certain assumptions the only functional form that is homogeneous of degree zero is precisely the one above.

We will assume that there is a winner who takes all, i.e. the war does not end in a stalemate. Assume that a fixed proportion of the war effort, say $k$, cannot be recovered by the winner, with $0 \leqslant k \leqslant 1$. The parameter $k$ is the marginal cost of effort.

For simplicity we assume, as it is customary in the literature, that players are risk-neutral. Thus, the payoff of, say player 1, if he wins the contest is $V_{1}+V_{2}-k\left(e_{1}+e_{2}\right)$ and zero otherwise. Let $V \equiv V_{1}+V_{2}$. Expected payoff of player $i$, denoted by $E \pi_{i}$, is $E \pi_{i}=p_{i}\left(V-k\left(e_{1}+e_{2}\right)\right)$. Finally we assume that information is complete and that the equilibrium concept is subgame perfection.

The game is characterized by four parameters, $V_{2} / V, k, \lambda, \gamma$. In order to analyze how the solution of the game depends on those parameters, we will proceed as follows. First, in Section 3 we solve the case where CSF are proportional and symmetric. In Section 4 we consider CSF which are symmetric but non proportional and in Section 5 we consider CSF which are non symmetric but proportional. The analysis in these last two sections complements the one in Section 3 and allows to highlight the role of $\gamma$ and $\lambda$ respectively.

\footnotetext{
9 We describe payoff-relevant events only. But the first stage can be envisioned as a summit between the leaders of the two countries where they sign a non-aggression treaty and, under the table, one of the leaders gets the transfer.

10 See Clausewitz (1832), Chapters 7 and 8 for a brief description of the role of chance in war.
} 


\section{The game with symmetric and proportional CSF}

In this case, the CSF reads for $e_{1}+e_{2}>0$,

$$
p_{i}=\frac{e_{i}}{e_{1}+e_{2}}, \quad i=1,2
$$

Thus, the expected payoff of player $i$, is

$$
E \pi_{i}=\frac{e_{i} V}{e_{1}+e_{2}}-k e_{i} .
$$

We solve the game backwards. Since no player has to move in the fourth stage, let us begin by analyzing the third stage. Setting $\partial E \pi_{i} / \partial e_{i}=0$, we get:

$$
e_{1}\left(e_{2}\right)=\sqrt{\frac{V e_{2}}{k}}-e_{2} \text { and } e_{2}\left(e_{1}\right)=\sqrt{\frac{V e_{1}}{k}}-e_{1},
$$

which implies $e_{i}=V / 4 k$.

To completely analyze this stage of the game we have to distinguish between the following possibilities: both players are unconstrained; both players are constrained or just one player is constrained. Let us analyze each of these cases in turn.

Case 3.1. Both players are unconstrained.

This case arises iff the resources in the hands of each player are larger than the solution to (3.3), i.e. $V \leqslant 4 k V_{1}$ and $V \leqslant 4 k V_{2}$. Since $V_{2}>V_{1}$, this is equivalent to $k \geqslant 0.5$, and $V_{2} / V \geqslant 1 / 4 k$. Then, equilibrium occurs at $e_{1}^{*}=e_{2}^{*}=V / 4 k$, and payoffs amount to $E \pi_{1}^{*}=E \pi_{2}^{*}=V / 4$.

Case 3.2. Both players are constrained.

This case arises iff $\partial E \pi_{i}\left(V_{1}, V_{2}\right) / \partial e_{i}>0$, which implies, $k<V_{2} / V$. We see that equilibrium occurs at $e_{1}^{*}=V_{1}$ and $e_{2}^{*}=V_{2}$, and payoffs amount to $E \pi_{1}^{*}=V_{1}(1-k)$ and $E \pi_{2}^{*}=V_{2}(1-k)$.

Case 3.3. Player 1 is unconstrained and player 2 is constrained.

This case arises iff the resources in the hand of player 2 are smaller than the solution to (3.3), i.e. $V>4 k V_{2}$, and the best reply of player 1 to $V_{2}\left(e_{1}\left(V_{2}\right)\right.$ described in (3.3)) is smaller than $V_{1}$, i.e. $\sqrt{V V_{2} / k}-V_{2} \leqslant V_{1}$, or equivalently, $V_{2} / V<\min \{k, 1 / 4 k\}$. Equilibrium occurs at

$$
e_{1}^{*}=\sqrt{\frac{V V_{2}}{k}}-V_{2} \text { and } e_{2}^{*}=V_{2} .
$$

Payoffs amount to

$$
E \pi_{1}^{*}=V+k V_{2}-2 \sqrt{V V_{2} k} \text { and } E \pi_{2}^{*}=\sqrt{V V_{2} k}-k V_{2} .
$$

In Fig. 1 below we illustrate the three possible cases. The increasing line corresponds to $V_{2} / V=k$, and the decreasing line corresponds to $V_{2} / V=1 / 4 k$.

Case 3.1 occurs in the area above the decreasing line. Case 3.2 occurs in the area to the left of the increasing line. Finally, Case 3.3 occurs in the area to the right of the increasing line and below the decreasing line.

We are now ready to analyze the second stage of the game by comparing the expected payoffs obtained under war with the payoffs in the case of peace, assuming that no transfers have been made in the first stage. Then, peace occurs iff $E \pi_{i} \leqslant V_{i}, i=1,2$.

If both players are unconstrained, $V / 4 \leqslant k V_{1}, V / 4 \leqslant k V_{2}$, since $k \leqslant 1, E \pi_{i} \leqslant V_{i}$ for all $i=1,2$. Thus, war in this case is not profitable.

If both players are constrained, $E \pi_{i}=V_{i}(1-k)$ for all $i=1,2$, which confirms that war is not profitable either. We record these findings in the following proposition.

Proposition 1. If both players are unconstrained or both players are constrained, no war is declared in equilibrium in the absence of transfers.

The interpretation of this result is the following: In Case 3.1 both players are not very different and the technology of recovery of the spoils of war is not very efficient (i.e. $k$ larger than 0.5 ). Therefore, aggression does not pay because 


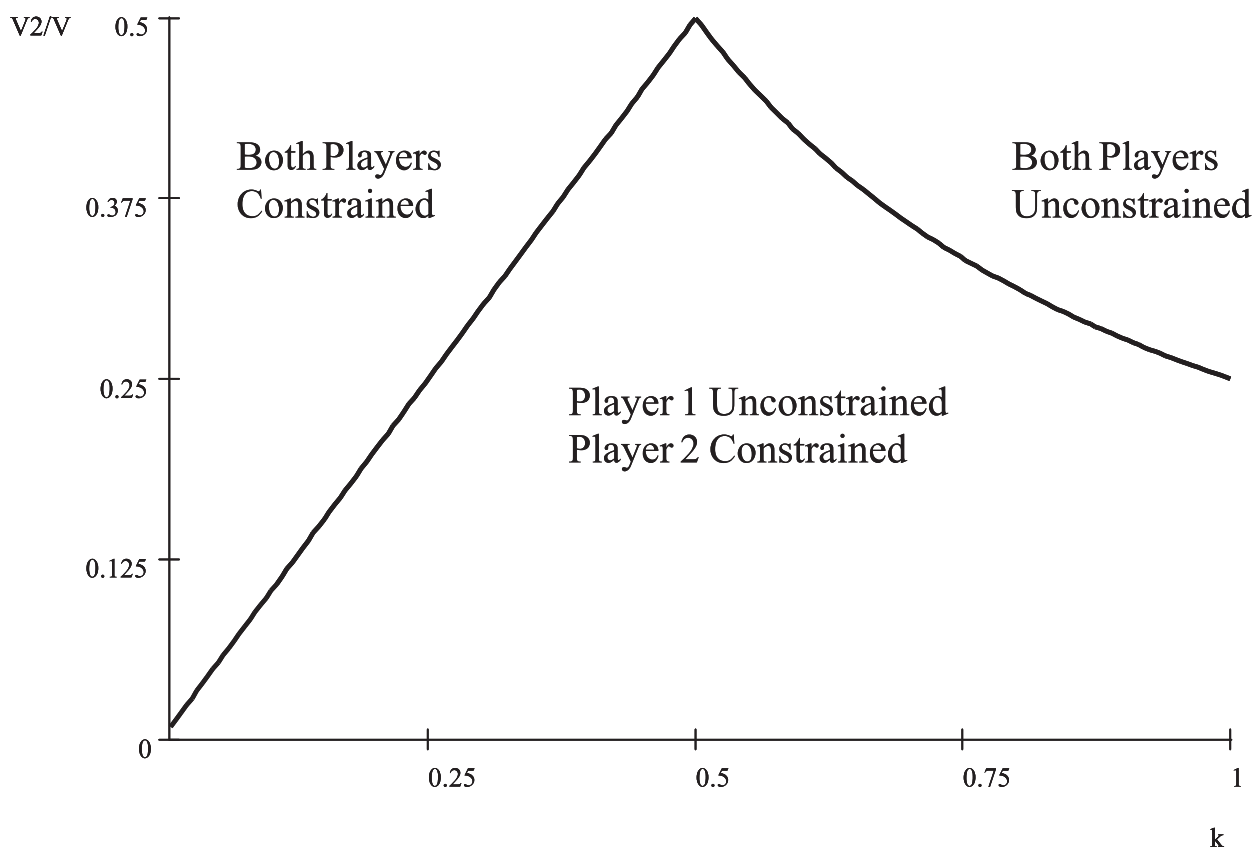

Fig. 1. The three cases: Areas in which the players are constrained.

it entails a small expected gain and a large loss of resources. War in Case 3.2 entails too much destruction because both players commit all their resources to the conflict, and since the probability of winning is proportional to war efforts, in the most favorable case $(k=0)$ they can only expected to gain their initial resources.

The analysis of Case 3.3 is far more interesting. Recall that in this case, $V_{2} / V \leqslant \min \{k, 1 / 4 k\}$. Peace occurs iff

$$
E \pi_{1}^{*}=V+k V_{2}-2 \sqrt{V V_{2} k} \leqslant V_{1}, \quad \text { or equivalently } \frac{V_{2}}{V} \leqslant \frac{4 k}{(1+k)^{2}},
$$

and

$$
E \pi_{2}^{*}=\sqrt{V V_{2} k}-k V_{2} \leqslant V_{2}, \quad \text { or equivalently } \frac{k}{(1+k)^{2}} \leqslant \frac{V_{2}}{V} .
$$

The inequality $V_{2} / V \leqslant 4 k /(1+k)^{2}$ holds in Case 3.3 since $V_{2} / V \leqslant \min \{k, 1 / 4 k\}$, and $k \leqslant 4 k /(1+k)^{2}$ for all $k \in[0,1]$. Thus, it is never in the interest of player 1 to declare war. However, inequality (3.7) not always hold, thus if $V_{2} / V<k /(1+k)^{2}$ player 2 has an incentive to declare war. This result is summarized in the next proposition.

Proposition 2. Suppose Case 3.3 holds. In the absence of transfers, war is declared by player 2 iff $V_{2} / V<k /(1+k)^{2}$. For any other values of the parameters, peace is the equilibrium outcome of the game.

Proposition 2 says that if player 1 is sufficiently rich with respect to player 2, the poor player has an incentive to declare war. The poor player declares war in the hope of becoming rich. But the effect of $k$ is contrary to what intuition might suggest, which is that when the marginal cost of war is high, war would not pay off. This counterintuitive result comes from the fact that the resources committed to war by player 1 decrease with $k$ and, thus, the larger $k$ the larger is the probability that player 2 wins the war. This makes the payoff for player 2 in the case of war increasing in $k$ and explains the result.

In Fig. 2 below we picture the function $V_{2} / V=k /(1+k)^{2}$ as a dotted line. The area enclosed by the three lines corresponds to parameters for which there is peace. The area below the dotted line corresponds to values of parameters where 2 declares war if no transfers have been made in the first stage.

A rough estimate of the probability that war arises can be obtained by assuming that $k \times V_{2} / V$ is uniformly distributed in $[0,1] \times[0,0.5]$. If so, the probability of war when no transfer has been made yet, denoted by $\operatorname{Pr}(\operatorname{war} N T)$ is

$$
\operatorname{Pr}(\operatorname{war} N T)=\int_{0}^{1}\left(\int_{0}^{\frac{k}{(1+k)^{2}}} 2 d x\right) d k=0.38629 .
$$




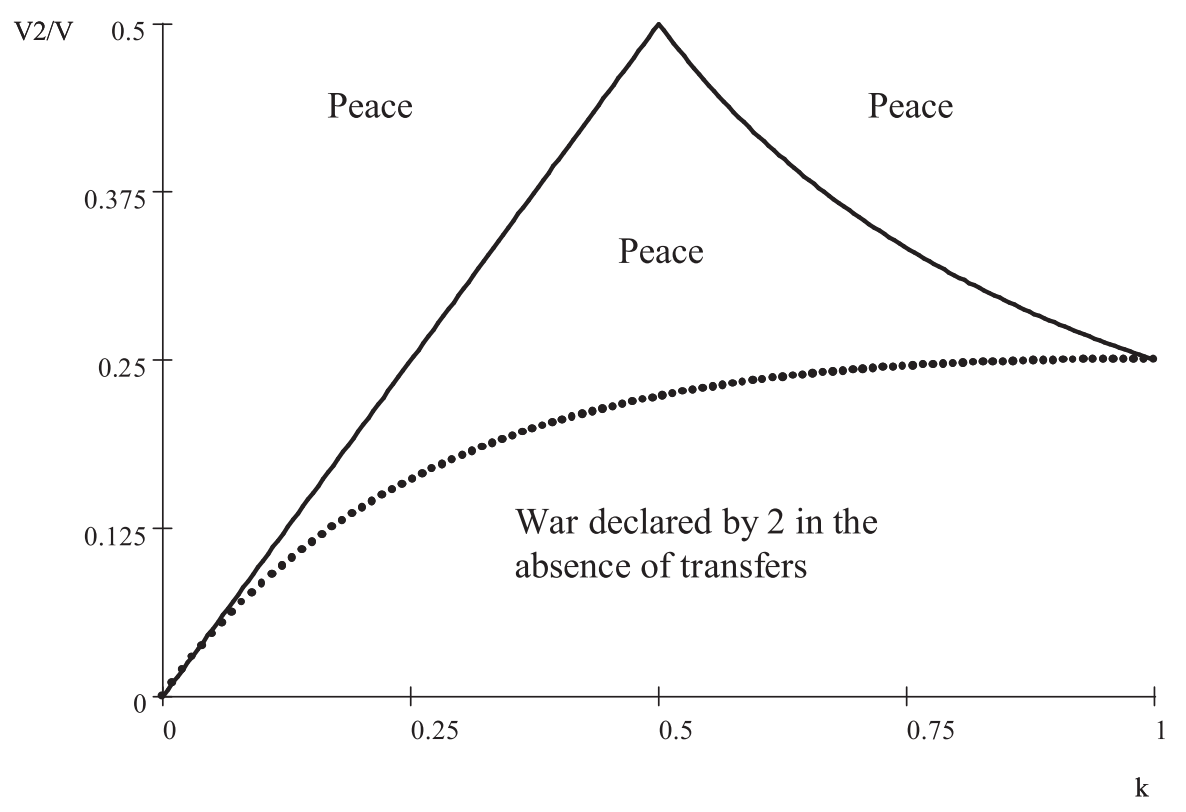

Fig. 2. War and peace in absence of transfers.

Now we are ready for the analysis of the first stage of the game. In particular we look for a transfer $T$ from player 1 to player 2 with the following properties:

1. Before the transfer, equilibrium means war. That is, Case 3.3 occurs and war is declared by player $2, V_{2} / V<k /(1+k)^{2}$.

2. After the transfer, both players are better off than if there had being a war. That is,

$$
-k \frac{V_{2}}{V}+\sqrt{\frac{V_{2}}{V} k} \leqslant \frac{V_{2}+T}{V} \leqslant-k \frac{V_{2}}{V}+2 \sqrt{\frac{V_{2}}{V} k},
$$

where the first (respectively the second) inequality corresponds to the expected value of player 2 (respectively player 1 ) before the transfer being smaller than his resources after the transfer.

3. After the transfer, peace is an equilibrium outcome.

Either we are in Case 3.1, i.e.,

$$
\frac{1}{4 k} \leqslant \frac{V_{2}+T}{V}, \quad k \geqslant 0.5,
$$

or in Case 3.3 with peace,

$$
\frac{k}{(1+k)^{2}} \leqslant \frac{V_{2}+T}{V}<\min \left(\frac{1}{4 k}, k\right)
$$

or in Case 3.2,

$$
k<\frac{V_{2}+T}{V}<\frac{1}{4 k}
$$

If $T$ satisfies conditions 1,2 and 3, we will say that a peace agreement is feasible.

In Fig. 2 we visualize the possible cases that can occur. For $k=1$, after the transfer we can only be in Case 3.1, the area above the decreasing line. For $k \in[0.5,1)$, after the transfer we can be either in Case 3.1 or in Case 3.3, but if Case 3.1 can be achieved with a certain transfer, Case 3.3 can be achieved with a smaller transfer (see Appendix A, Lemma 1). For $k \in(0,0.5)$, after the transfer we can be either in Case 3.3 or in Case 3.2, but if Case 3.2 can be achieved with a certain transfer, Case 3.3 can be achieved with a smaller transfer (see Appendix A, Lemma 2). Therefore, for all $k \in(0,1)$ we only have to explore the existence of a peace agreement such that after the transfer we are in Case 3.3. Summing up, we need to study under what conditions there is a transfer $T$ such that

$$
\max \left(\frac{k}{(1+k)^{2}},-k \frac{V_{2}}{V}+\sqrt{\frac{V_{2}}{V} k}\right) \leqslant \frac{V_{2}+T}{V} \leqslant \min \left(\frac{1}{4 k}, k,-k \frac{V_{2}}{V}+2 \sqrt{\frac{V_{2}}{V}} k\right) .
$$




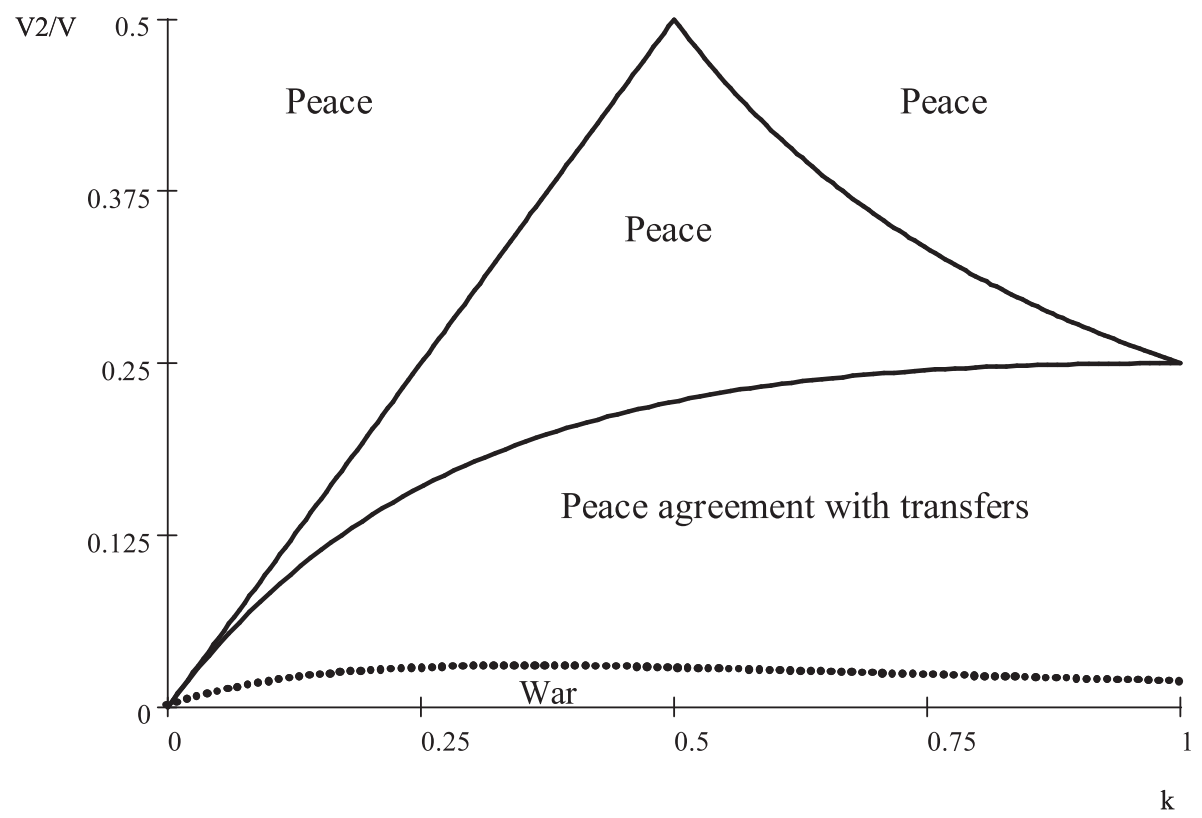

Fig. 3. War and peace with transfers.

In Fig. 2 is clear that the minimal transfer that will avoid war by player 2 should be such that this player is indifferent between war and peace, that is $\left(V_{2}+\hat{T}\right) / V=k /(1+k)^{2}$. But we have to be sure that player 1 will be better off after the transfer than if there had being a war, which is equivalent to require that

$$
\frac{k}{(1+k)^{2}} \leqslant-k \frac{V_{2}}{V}+2 \sqrt{\frac{V_{2}}{V} k .}
$$

But this will only happen if $V_{2} / V \geqslant x_{1}(k)$, where $x_{1}(k)$ is the solution to $k /(1+k)^{2}=-k x+2 \sqrt{x k}$. We show in Lemma 4 that $x_{1}(k)$ exists and $x_{1}(k) \in\left[0, k /(1+k)^{2}\right)$. So, $x_{1}(k)$ can be interpreted as the minimal relative resources in hands of player 2 that will make player 1 be indifferent between making the transfer or go to war in the first place. If the relative resources in hands of player 2 are less than this quantity, the required transfer becomes too expensive for player 1 . In the following proposition we formalize these arguments.

Proposition 3. For each $k \in(0,1]$, a peace agreement is feasible if and only if $V_{2} / V>x_{1}(k)$. The minimal transfer, $\hat{T}$, that avoids war is such that it makes player 2 be indifferent between war and peace, that is, $\left(V_{2}+\hat{T}\right) / V=k /(1+k)^{2}$.

Fig. 3 summarizes the above result. The area below the dot line $\left(x_{1}(k)\right)$ represents the area where a peace agreement is impossible. If resource inequality is very large, negotiations cannot avoid war because the minimal transfer that will stop player 2 to declare war is too expensive for player 1 . Above the $x_{1}(k)$ line, peace is possible. The transfer that avoids war increases with $k$, thus reflecting that, as we remarked before, the war effort of player 1 decreases with $k$. So a high $k$ increases the probability that player 2 wins the war and therefore increases the transfer that makes player 2 peaceful.

It is worth noting that in the worst situation, a peace agreement can be reached when the resources of the poorest player are at least 2.9 percent of the total resources. Again, an idea of the probability that war will arise when transfers can be made is obtained assuming that $k \times V_{2} / V$ is uniformly distributed in $[0,1] \times[0,0.5]$. The probability of war with transfers denoted by $\operatorname{Pr}(\operatorname{war} T)$ is

$$
\operatorname{Pr}(\operatorname{war} T)=\int_{0}^{1}\left(\int_{0}^{x_{1}(k)} 2 d x\right) d k=0.046496 .
$$

This probability is, approximately, eight times smaller that the probability of war without transfers (0.38629).

\section{The game with a symmetric CSF}

In this section we consider a generalized symmetric form of the contest success function used in the previous section. Instead of offering a complete analysis of this case (which will be cumbersome because of the algebra involved) we will 
concentrate on the analysis of outcomes that were not possible in the previous section, namely: 1) The existence of war when both players are either unconstrained or constrained. 2) The incentives for a rich player to attack. We will also study the suitability of transfers to stop war. We will see that when players are unconstrained a peaceful arrangement is always possible. Unfortunately, in the other cases there are instances in which no transfer can stop war.

Suppose that the CSF is of the following form for $e_{1}^{\gamma}+e_{2}^{\gamma}>0$,

$$
p_{i}=\frac{e_{i}^{\gamma}}{e_{1}^{\gamma}+e_{2}^{\gamma}}, \quad i=1,2 .
$$

This is the CSF proposed by Tullock (1980) and used ubiquitously in the literature. It reduces to the general form postulated in Section 3 when $\gamma=1$. Until further notice we assume that $0 \leqslant \gamma \leqslant 1$. This condition implies that expected payoffs are concave in the own effort.

Expected payoffs for player $i$, assuming that war has been declared are

$$
E \pi_{i}=p_{i}\left(V-k\left(e_{1}+e_{2}\right)\right)=\frac{e_{i}^{\gamma}}{e_{1}^{\gamma}+e_{2}^{\gamma}}\left(V-k\left(e_{1}+e_{2}\right)\right) .
$$

Setting $\partial E \pi_{1} / \partial e_{1}=0, i=1,2$, and solving we obtain

$$
e_{1}^{*}=e_{2}^{*}=\frac{\gamma V}{2 k(\gamma+1)} \text { and } E \pi_{1}^{*}=E \pi_{2}^{*}=\frac{V}{2(\gamma+1)} .
$$

Case 4.1. Both players are unconstrained.

This case arises if the following inequality holds,

$$
V_{1} \geqslant \frac{\gamma V}{2 k(\gamma+1)} \text { and } V_{2} \geqslant \frac{\gamma V}{2 k(\gamma+1)} .
$$

Since $V_{1}>V_{2}$, if the second inequality holds, the first inequality also holds.

For war to be a rational option, we need the following:

$$
\frac{V}{2(\gamma+1)}>V_{1} \text { or } \frac{V}{2(\gamma+1)}>V_{2} \text {. }
$$

We first notice that it is impossible that both inequalities occur, because adding them up we get $V /(\gamma+1)>V$ which is impossible. This implies that player 1 has no incentive to go to war because if it had, player 2 would also have incentives to declare war (since $V_{1}>V_{2}$ ). Thus, we are left with the case where only the second inequality in (4.5) holds, so the second country has an incentive to go to war. Notice that, contrarily to the case in which $\gamma=1$, war is now possible: Indeed, the occurrence of war is equivalent to

$$
V_{2} \geqslant \frac{\gamma V}{2 k(\gamma+1)} \text { and } \frac{V}{2(\gamma+1)}>V_{2},
$$

which is possible whenever $\gamma<k$. Our next result summarizes this discussion.

Proposition 4. When the CSF are of the form (4.1), and both players are unconstrained, in the absence of transfers, no war is declared for any $\gamma \geqslant k$. When $\gamma<k$, war is declared by player 2 for any value of $V_{2} / V \in[\gamma / 2 k(\gamma+1), 1 / 2(\gamma+1))$.

We see that the occurrence of war depends on two factors. On the one hand, the probability of winning the war should not depend very much on war efforts relative to the marginal cost of war, $k$. For a small $\gamma$ the poor player has a chance of winning the war without much effort which implies a sizeable loot should war be won. On the other hand, the ratio of resources of player 2 with respect to those of player 1 should not be too high-because otherwise player 2 risks a lot-nor too low, because in this case player 2 is constrained.

An important consequence of this result is that when $\gamma \rightarrow 0$, war is possible for any value of $V_{2} / V$. In other words, here war is possible even in the absence of inequality. This is because when the success of war is not very sensitive to war efforts, both players use only a small part of their resources in war and the loot of the winner is considerable.

Let us study the equilibrium in the first stage of the game. Consider the minimum transfer that leaves player 2 indifferent between peace and war, namely $V_{2}+\hat{T}=V / 2(\gamma+1)$. Notice that $\hat{T}$ is always smaller than $V_{1}$ (if it were not, $V / 2(\gamma+1)-$ $V_{2}>V_{1}$, which is impossible). After the transfer, both players will be better off than if they had a war, player 1 will still be unconstrained and no one will have incentives to declare war. The following proposition proves that this is indeed the case.

Proposition 5. When the CSF are of the form (4.1) and both players are unconstrained, a peace agreement is feasible. The minimal transfer that avoids war is such that it makes player 2 be indifferent between war and peace, that is $V_{2}+\hat{T}=V / 2(\gamma+1)$. 
The interpretation of this result is that, as we saw before, war is a rational option for player 2 when it is a kind of lottery, i.e. the outcome of the war does not depend much on war efforts. But in this case a transfer acts as a costless lottery that leaves both players better off.

Case 4.2. Both players are constrained.

This case arises iff $\partial E \pi_{i}\left(V_{1}, V_{2}\right) / \partial e_{i}>0$, or equivalently:

$$
\begin{aligned}
& \frac{V_{2}^{\gamma} \gamma}{\left(V_{1}^{\gamma}+V_{2}^{\gamma}\right)} V(1-k)>V_{1} k ; \\
& \frac{V_{1}^{\gamma} \gamma}{\left(V_{1}^{\gamma}+V_{2}^{\gamma}\right)} V(1-k)>V_{2} k .
\end{aligned}
$$

Notice first that player 1 constrained (inequality (4.7)) implies player 2 constrained (inequality (4.8)). Notice also that no player is constrained if $\gamma=0$.

In this case, $E \pi_{i}=\left(V_{i}^{\gamma} /\left(V_{1}^{\gamma}+V_{2}^{\gamma}\right)\right) V(1-k), i=1,2$. Since the probability of winning for player 1 is increasing with $\gamma$,

$$
\frac{V_{1}^{\gamma}}{\left(V_{1}^{\gamma}+V_{2}^{\gamma}\right)} V(1-k) \leqslant \frac{V_{1}}{\left(V_{1}+V_{2}\right)} V(1-k)=V_{1}(1-k) \leqslant V_{1},
$$

which implies that player 1 has no incentive to declare war.

However, contrary to the case in which $\gamma=1$, if $\gamma<1$ war is possible. For player 2 to have an incentive to declare war, $E \pi_{i}>V_{2}$ should hold. That is,

$$
\frac{V_{2}}{V}<\frac{V_{2}^{\gamma}}{\left(V_{1}^{\gamma}+V_{2}^{\gamma}\right)}(1-k)
$$

Notice that for $\gamma<1$, and $k$ sufficiently close to 0 , (4.10) always holds. Firstly because for $k \simeq 0$, both players are constrained no matter the distribution of resources (see (4.7) and (4.8)). Secondly because since $V_{2}<V_{1}, V_{2}^{\gamma} /\left(V_{1}^{\gamma}+V_{2}^{\gamma}\right)$ is decreasing in $\gamma$. Also notice that if $\gamma=1,(4.10)$ never holds as we proved in Section 3.

When $k$ is sufficiently close to 0 , player 2 always has an incentive to declare war and no transfer will avoid war. The minimal transfer that will stop player 2 from declaring war should be such that resources of both players are almost equalized. But then, player 1 will not be better off because before the transfer he expects in the worse case $(\gamma=0)$ approximately half of the resources.

Proposition 6. When the CSF are of the form (4.1), $\gamma \in(0,1)$ and $k$ is sufficiently close to 0 , war is always declared by player 2 and there is no transfer that avoids war.

The interpretation of this result is that when the war is costless it proves to be too good an option because the transfers that would make player 2 peaceful are too costly for player 1. A more complete analysis of this case, including more general conditions under which war can be stopped by the appropriate transfer are available under request.

Next we assume that $\gamma>1$. In this case, the expected payoffs of a player are not necessarily concave on the strategy of this player so the existence of equilibrium cannot be guaranteed by the standard Kakutani fixed point theorem. In the case of pure Rent-Seeking games an analysis of Nash equilibrium was made by Perez-Castrillo and Verdier (1992). Since our goal is not to offer a complete characterization of equilibria in this case but to highlight new cases that could not arise in the framework of Section 3, we will content with showing that, in some instances, in equilibrium the rich player has incentives to attack and that no transfer can stop war. Indeed, we can show the following:

Proposition 7. When the CSF are of the form (4.1), $\gamma>1$ and $k$ is sufficiently close to 0 , both players are constrained. War is always declared by player 1 and there is no transfer that avoids war.

In this case, as in Proposition 6, war is caused by the fact that when $k$ is close to zero, the cost of war is small. The transfer mechanism fails to appease in both cases because any resources poured onto a player are spent by this player on further increase of his military capabilities. The difference between the two last propositions is which country declares war: When $\gamma<1$ who is the winner of the war does not depend much on the resources used in war. Thus, the chances of the poor player of winning are larger than his share of resources in aggregate resources and this explains his willingness to attack. When $\gamma>1$ who is the winner depends very much on the number of resources committed to war. Thus, the chances of the rich player to win are larger than his share of resources in aggregate resources and this explains his willingness to attack. 


\section{The game with asymmetric and proportional CSF}

In this section we consider an asymmetric CSF in which the rich player has advantage in military proficiency. The purpose of this section is to study the impact of a superior military technology on outcomes. We show that: 1) When both players are unconstrained no player has incentives to declare war, no matter how high the military proficiency of the rich player is. 2) When both players are constrained, in some cases, the rich player has incentives to declare war but there is a transfer that avoids war. Thus we conclude that military superiority does not translate automatically in willingness to start a war and, again, the transfer mechanism is useful in deterring wars.

Consider a CSF of the following form for $\lambda e_{1}+e_{2}>0$,

$$
p_{1}=\frac{\lambda e_{1}}{\lambda e_{1}+e_{2}} \text { and } p_{2}=\frac{e_{2}}{\lambda e_{1}+e_{2}}, \quad \lambda \in[1, \infty) .
$$

It reduces to the form postulated in Section 3 when $\lambda=1$. We assume $\lambda \geqslant 1$. The motivation for this assumption is that in many cases, war proficiency is positively correlated with relative wealth, i.e. countries that are good at producing wealth are also good at producing weapons.

Expected payoffs for players 1 and 2 when war is declared are

$$
E \pi_{1}=\frac{\lambda e_{1}}{\lambda e_{1}+e_{2}}\left(V-k\left(e_{1}+e_{2}\right)\right) \text { and } E \pi_{2}=\frac{e_{2}}{\lambda e_{1}+e_{2}}\left(V-k\left(e_{1}+e_{2}\right)\right) .
$$

From (5.2), setting $\partial E \pi_{i} / \partial e_{i}=0, i=1,2$, and solving we obtain

$$
e_{1}^{*}=\frac{V}{2 k(1+\sqrt{\lambda})} \quad \text { and } \quad e_{2}^{*}=\frac{V \sqrt{\lambda}}{2 k(1+\sqrt{\lambda})} .
$$

Case 5.1. Both players are unconstrained.

Consider first the case where both countries are unconstrained, that is

$$
\frac{V}{2 k(1+\sqrt{\lambda})} \leqslant V_{1} \text { and } \frac{V \sqrt{\lambda}}{2 k(1+\sqrt{\lambda})} \leqslant V_{2} .
$$

The inequalities in (5.4) can be written as

$$
k \geqslant \frac{\sqrt{\lambda}}{(1+\sqrt{\lambda})} \text { and } \frac{V_{2}}{V} \geqslant \frac{\sqrt{\lambda}}{2 k(1+\sqrt{\lambda})} .
$$

Expected payoffs in case of war are,

$$
E \pi_{1}=\frac{V \sqrt{\lambda}}{2(1+\sqrt{\lambda})} \text { and } E \pi_{2}=\frac{V}{2(1+\sqrt{\lambda})} .
$$

Notice that the total expected payoff under war is $V / 2$. So player 1 has no incentive to declare war because his expected payoff is less than $V_{1}$. Player 2 had no incentive to declare war when $\lambda=1$, so he cannot have any incentive to declare war when $\lambda>1$ because his expected payoff is decreasing with $\lambda$.

The following proposition summarizes this result.

Proposition 8. When the CSF are of the form (5.1) and both players are unconstrained, peace is an equilibrium outcome in absence of transfers.

It is noteworthy that the military advantage of player 1 never translates in incentives to declare war. This is because player 1 risks too much in a war, more than half of total resources. This is not the case if both players are constrained as shown next.

Case 5.2. Both players are constrained.

This case arises iff $\partial E \pi_{i}\left(V_{1}, V_{2}\right) / \partial e_{i}>0$, or equivalently:

$$
V V_{2}>k\left(\lambda V_{1}^{2}+2 V_{1} V_{2}+V_{2}^{2}\right) \text { and } V \lambda V_{1}>k\left(\lambda V_{1}^{2}+2 V_{1} V_{2}+V_{2}^{2}\right) \text {. }
$$

Notice first that if player 1 is constrained, player 2 is also constrained because $\lambda>1$, and $V_{1}>V_{2}$. Therefore, if the first of the above inequalities holds, both players are constrained. 
Expected payoffs read:

$$
E \pi_{1}\left(V_{1}, V_{2}\right)=\frac{\lambda V_{1} V(1-k)}{\lambda V_{1}+V_{2}} \text { and } E \pi_{2}\left(V_{1}, V_{2}\right)=\frac{V_{2} V(1-k)}{\lambda V_{1}+V_{2}} .
$$

The probability of winning for player 2 decreases with the military proficiency of player 1 , so if player 2 had no incentive to declare war when $\lambda=1$, he does not have one now. The probability of winning for player 1 increases with his military proficiency, thus, if the cost of war is not too high relative to the inequality of resources and his military proficiency, player 1 has an incentive to declare war. The following proposition formally states this result. The condition under which player 1 will declare war follows directly from $E \pi_{1}\left(V_{1}, V_{2}\right)>V_{1}$.

Proposition 9. When the CSF are of the form (5.1) and both players are constrained, in the absence of transfers war is declared by player 1 if and only if $k<V_{2}(\lambda-1) / V \lambda$. Player 2 has no incentive to declare war.

In the next proposition we study the possibility of avoiding war by transfers, in this case from the poor to the rich country. We just give a sufficient condition that guarantees the existence of a transfer from the poor to the rich that avoids war. The sufficient condition guarantees that after the transfer both players are still constrained.

Proposition 10. When the CSF are of the form (5.1), both players are constrained, and war is declared by player 1, a peace agreement is feasible if $V_{2}(\lambda-1) / V \lambda<V V_{2} /\left(\lambda V_{1}^{2}+2 V_{1} V_{2}+V_{2}^{2}\right)$. The minimal transfer, $\hat{T}$, that avoids war is such that makes player 1 be indifferent between war and peace.

To complete the analysis of this asymmetric case, we would need to study what will happen in the situation where player 1 is unconstrained and player 2 is constrained. The analysis of this part is more complicated, and we believe that will not bring any new insights. What is important in the analysis of the asymmetric case is the fact that it is the rich country that has an incentive to declare war, and that a transfer from the poor to the rich avoids war.

\section{The two period model}

A possible criticism of our previous findings is that transfers usually occur in a dynamic environment in which the question of war and peace can be much more complicated than in our model. A full analysis of a dynamic model of war is beyond the scope of this paper but in this section we consider a simple extension of our model to a two period model. We show that war is declared in equilibrium in the first or in the second period in the two period model iff war is declared in equilibrium in the one period model. Thus, in this case, the consideration of an extra period does not change qualitatively our analysis of war and transfers.

There are two periods. Players have resources $V_{1}$ and $V_{2}$ in each period with $V_{1}>V_{2}$. We assume that players do not discount the future, that resources cannot be accumulated from the first to the second period, and that players cannot borrow against future resources.

In the first period, they play the game explained in Section 3. If there is war the winner takes the loot and consumes aggregate resources in the second period. The payoff of a player if he wins the war is $2 V_{1}+2 V_{2}-k\left(e_{1}+e_{2}\right)$ and zero otherwise. Expected payoff of player $i$, denoted by $E \pi_{i}$, is: $E \pi_{i}=p_{i}\left(2 V-k\left(e_{1}+e_{2}\right)\right)$.

If there is peace they consume their resources and go to the second period where an identical game is played.

Let $T_{i}^{t}$ the transfer made by player $i$ in period $t$ (if it is positive $i$ makes a transfer to $j$, if it is negative $i$ receives the transfer from player $j$ ). In the case of peace in both periods, payoff to player $i$ is $2 V_{i}+T_{i}^{1}+T_{i}^{2}, i=1,2$.

If war is declared in the second period, since peace was the outcome of the first period the expected payoff of player $i$ is: $E \pi_{i}=V_{i}+T_{i}^{1}+p_{i}\left(V-k\left(e_{1}+e_{2}\right)\right)$.

Assume that $p_{i}$ is proportional to war effort as described in Section 3.

We solve the game backwards.

Case 6.1. Both players are unconstrained in the second period.

Given our analysis of one period, if both player are unconstrained in the second period $\left(k \geqslant 0.5\right.$, and $\left.V_{2} / V \geqslant 1 / 4 k\right)$, war will not be declared in this period.

In case war is declared in period 1 , the expected payoff of player $i$ is: $E \pi_{i}=e_{i} 2 V /\left(e_{1}+e_{2}\right)-k e_{i}$. The equilibrium of the game depends on players being constraint or not in the first period.

(a) Suppose that players are not constrained in the first period. The effort in case of war will be $e_{i}^{*}=V / 2 k$.

Notice that the consideration of the future makes agents more aggressive than in the one-period game because they are fighting to get a bigger price.

This case will occur whenever $V_{2} / V \geqslant 1 / 2 k$. Since $V_{2} / V \leqslant 1 / 2$, this is only possible if $k=1$ and $V_{2} / V=1 / 2$.

If war is declared in period 1 , the expected payoff of the players will be $V / 2$. But if no war is declared, they will get $2 V_{i}=V$. Thus, peace in period 1 and peace in period 2 is an equilibrium outcome. 
(b) Suppose that both players are constrained in the first period. That is, $\partial E \pi_{i}\left(V_{1}, V_{2}\right) / \partial e_{i}>0$, which implies $V_{2} / V>$ $k / 2$.

If war is declared in period 1 , the expected payoff of the players will be $V_{i}(2-k)$. But $V_{i}(2-k) \leqslant 2 V_{i}$. Thus, peace in period 1 and peace in period 2 is an equilibrium outcome.

(c) Suppose that in the first period player $\mathbf{2}$ is constrained but player $\mathbf{1}$ is not. That is, $V / 2 k>V_{2}$, and the best reply of player 1 to $V_{2}$ is smaller than $V_{1}$, i.e. $\sqrt{2 V V_{2} / k}-V_{2} \leqslant V_{1}$, or equivalently, $V_{2} / V \leqslant \min \{k / 2,1 / 2 k\}=k / 2$.

If war is declared in period 1 , the expected payoff of the players will be $E \pi_{1}^{*}=2 V+k V_{2}-2 \sqrt{2 V V_{2} k}$ and $E \pi_{2}^{*}=$ $\sqrt{2 V V_{2} k}-k V_{2}$.

War will not be declared by player 1 if $E \pi_{1}^{*} \leqslant 2 V_{1}$, which is equivalent to $V_{2} / V \leqslant 8 k /(k+2)^{2}$. This inequality holds because $V_{2} / V \leqslant k / 2$ and $k / 2<8 k /(k+2)^{2}$. Thus, it is never in the interest of player 1 to declare war.

War will not be declared by player 2 if $E \pi_{2}^{*} \leqslant 2 V_{2}$, which is equivalent to $V_{2} / V \geqslant 2 k /(2+k)^{2}$. Since no player is constrained in the second period, $V_{2} / V \geqslant 1 / 4 k$, and $1 / 4 k \geqslant 2 k /(2+k)^{2}$, player 2 will not have any interest in declaring war. Thus, peace in period 1 and peace in period 2 is an equilibrium outcome.

Case 6.2. Both players are constrained in the second period.

In case of war in the first period, agents will be more aggressive that they would be if war only occurred in the second period. Since agents are constrained in the second period, they will also be constrained in the first period.

If war is declared in period 1 , the expected payoff of the players will be $V_{i}(2-k)$. But $V_{i}(2-k) \leqslant 2 V_{i}$. Thus, peace in period 1 and peace in period 2 is an equilibrium outcome.

Summarizing our results so far, we obtain a result like Proposition 1.

Proposition 11. If both players are unconstrained or both players are constrained in the second period, no war is declared in equilibrium in the absence of transfers.

Case 6.3. In the second period player 1 is unconstrained and player 2 is constrained.

This is the case if $V_{2} / V<\min \{k, 1 / 4 k\}$.

(a) Suppose first that no agent has incentives to declare war in the second period. That is, $k /(1+k)^{2} \leqslant V_{2} / V$.

Since player 2 is constrained in the second period, he is also constrained in the first period. But player 1 can be constrained or not in the first period.

(a1) Suppose first that player 1 is also constrained in the first period. That is, $V_{2} / V>k / 2$. If war is declared, the expected payoff of player $i$ will be $V_{i}(2-k)$. But $V_{i}(2-k) \leqslant 2 V_{i}$. Thus, peace in period 1 and peace in period 2 is an equilibrium outcome.

(a2) Suppose that player 1 is unconstrained in the first period. That is, $V_{2} / V \leqslant k / 2$.

War will not be declared by player 1 if $E \pi_{1}^{*} \leqslant 2 V_{1}$ which is equivalent to $V_{2} / V \leqslant 8 k /(k+2)^{2}$. This inequality holds because $V_{2} / V \leqslant k / 2$ and $k / 2<8 k /(k+2)^{2}$.

War will not be declare by player 2 if $E \pi_{2}^{*} \leqslant 2 V_{2}$, which is equivalent to $V_{2} / V \geqslant 2 k /(2+k)^{2}$. This inequality holds because since war is not declared in period $2, V_{2} / V \geqslant k /(1+k)^{2}$, and since $k \leqslant 1, k /(1+k)^{2}>2 k /(2+k)^{2}$. Thus, peace in period 1 and peace in period 2 is an equilibrium outcome.

(b) Suppose that player 2 has incentives to declare war in the second period, but a transfer will avoid war. That is, $k /(1+k)^{2}>V_{2} / V>x_{1}(k)$ where $x_{1}(k)$ is the solution of $k /(1+k)^{2}=-k x+2 \sqrt{x k}$. The minimal transfer, $\hat{T}$, that avoids war is such that makes player 2 be indifferent between war and peace, that is, $\left(V_{2}+\hat{T}\right) / V=k /(1+k)^{2}$.

Since player 2 is constrained in the second period, he is also constrained in the first period. But player 1 can be constrained or not in the first period. Let us see both cases in turns.

(b1) Suppose first that player 1 is also constrained in the first period. That is, $V_{2} / V>k / 2$. (Notice that this implies that $k<1)$. If war is declared, the expected payoff of the players will be $V_{i}(2-k)$. Player 2 does not have incentives to declare war because $V_{2}(2-k)<V_{2}+\left(V_{2}+\hat{T}\right)$. Player 1 does not have incentives to declare war either because the inequality $V_{1}(2-k)<V_{1}+\left(V_{1}-\hat{T}\right)$, is equivalent to $V_{1} / V<\left(1+k+k^{2}\right) /(1-k)(1+k)$. The right-hand side of the above inequality is bigger than 1 . Thus, the inequality always hold. The transfer that this player has to make in the second period is smaller than what he will loose $\left(k V_{1}\right)$ in case of war.

(b2) Suppose that player 1 is not constrained in the first period. That is, $V_{2} / V \leqslant k / 2$.

If war is declared in period 1 , the expected payoff of the players will be $E \pi_{1}^{*}=2 V+k V_{2}-2 \sqrt{2 V V_{2} k}$ and $E \pi_{2}^{*}=$ $\sqrt{2 V V_{2} k}-k V_{2}$.

War will not be declared by player 1 if $E \pi_{1}^{*} \leqslant 2 V_{1}-\hat{T}$. Notice first that since the transfer avoids war in the second period, $V+k V_{2}-2 \sqrt{V V_{2} k} \leqslant V_{1}-\hat{T}$. The expected payoff for player 1 in case of war in the first period can be rewritten as: $E \pi_{1}^{*}=V+k V_{2}-2 \sqrt{V V_{2} k}+V-(2 \sqrt{2}-2) \sqrt{V V_{2} k}$. Thus, $E \pi_{1}^{*} \leqslant V_{1}-\hat{T}+V-(2 \sqrt{2}-2) \sqrt{V V_{2} k}$. Let us see that $V-(2 \sqrt{2}-2) \sqrt{V V_{2} k} \leqslant V_{1}$, which is equivalent to $V_{2} / V \leqslant(2 \sqrt{2}-2)^{2} k$. The last inequality always holds because, $V_{2} / V \leqslant$ $k / 2$ and $k / 2<(2 \sqrt{2}-2)^{2} k$. 
War will not be declared by player 2 if $E \pi_{2}^{*} \leqslant V_{2}+V_{2}+\hat{T}$. This inequality is equivalent to $\sqrt{2 k\left(V_{2} / V\right)}-(k+1)\left(V_{2} / V\right) \leqslant$ $\left(k /(k+1)^{2}\right)$. The left-hand side of the inequality takes its maximum at $V_{2} / V=k /\left(2(k+1)^{2}\right)$. For this value the left-hand side is equal to $k / 2(k+1)$ which for all $k \leqslant 1$ is always smaller or equal than $k /(k+1)^{2}$.

(c) Suppose that war is the outcome of the second period, and no transfer avoid war. That is, $V_{2} / V<x_{1}(k)$ where $x_{1}(k)$ is the solution of $k /(1+k)^{2}=-k x+2 \sqrt{x k}$. The expected payoffs in the second period will be $V+k V_{2}-2 \sqrt{V V_{2} k}$ for player 1 and $\sqrt{V V_{2} k}-k V_{2}$ for player 2 .

Player 1 will be constrained in the first period if $V_{2} / V>k / 2$. But this cannot be the case because $x_{1}(k) \leqslant k / 2$. Thus, player 1 is unconstrained and player 2 is constrained in the first period.

If war is declared in period 1 , the expected payoff of the players will be $E \pi_{1}^{*}=2 V+k V_{2}-2 \sqrt{2 V V_{2} k}$ and $E \pi_{2}^{*}=$ $\sqrt{2 V V_{2} k}-k V_{2}$.

War will not be declared by player 1 if $E \pi_{1}^{*} \leqslant V_{1}+V+k V_{2}-2 \sqrt{V V_{2} k}$. This inequality is equivalent to $V_{2} / V \leqslant$ $4 k(\sqrt{2}-1)^{2}$. This inequality always holds because $V_{2} / V \leqslant k / 2$, and $k / 2 \leqslant 4 k(\sqrt{2}-1)^{2}$.

Player 2 will not declare war in the first period if $E \pi_{2}^{*} \leqslant V_{2}+\sqrt{V V_{2} k}-k V_{2}$. This is equivalent to $V_{2} / V \geqslant(\sqrt{2}-1)^{2} k$. When this inequality holds peace is chosen in the first period but war is the outcome in the second period.

If $V_{2} / V<(\sqrt{2}-1)^{2} k$, player 2 will declare war. Let us see that no transfer will avoid war in this case.

The maximal transfer that player 1 is ready to concede is such that makes him indifferent between war and peace, that is:

$$
2 V+k V_{2}-2 \sqrt{2 V V_{2} k}=V_{1}-T+V+k V_{2}-2 \sqrt{V V_{2} k}
$$

The above equality implies that

$$
\frac{V_{2}+T}{V}=2 \sqrt{\frac{V_{2}}{V}} k(\sqrt{2}-1) .
$$

Notice also that since $V_{2} / V<(\sqrt{2}-1)^{2} k$, after the transfer the resources in hand of player 2 are at most $2(\sqrt{2}-1)^{2} k \leqslant k / 2$. Thus, after the transfer player 1 is still no constrained and player 2 is constrained.

Let us see that the transfer defined in (6.2) does not prevent player 2 to declare war.

Let $V_{2}^{\prime}=V_{2}+T$. For the transfer to prevent war it should happen that

$$
\sqrt{2 V V_{2}^{\prime} k}-k V_{2}^{\prime} \leqslant V_{2}^{\prime}+\sqrt{V V_{2} k}-k V_{2} \text {. }
$$

But notice that $\sqrt{2 V V_{2}^{\prime} k}-k V_{2}^{\prime}>V_{2}^{\prime}$ for all $V_{2}^{\prime} / V<2 k /(k+1)^{2}$. But since $V_{2}^{\prime} / V \leqslant 2(\sqrt{2}-1)^{2} k, V_{2}^{\prime} / V<2 k /(k+1)^{2}$. Thus, the transfer described in (6.2) will not avoid war. In this last case, war is declared in the first period.

The next proposition summarizes our results in this section.

Proposition 12. When player 1 is unconstrained and player 2 is constrained in the second period and allowing for transfers, war is declared in equilibrium in the first or in the second period in the two period model iff war is declared in equilibrium in the one period model.

Thus we see that the consideration of an extra period does not bring qualitatively any new insight to our analysis of war and transfers.

\section{Conclusions}

In this paper we presented a model of war where players are rational, information is complete and there are no binding agreements. We have shown that war can be avoided by transferring resources from one player to another in a variety of cases.

Clearly, our model is very simple. In order to have a broader picture, other factors such as dynamics, heterogeneous resources, asymmetric information and risk-averse players should be considered. ${ }^{11}$ Other functional forms of CSF and the cost of war should be tried as well. Also, the role of the characteristics of the population and their influence on the conflict should be considered, see e.g. Esteban and Ray (1999). A more challenging extension would be to assume more than two countries, i.e. a "region", and to look for the transfers that maintain peace in the region, see Piccione and Rubinstein (2004) for a similar problem. Other mechanisms of appeasement, such trade treaties or technology transfers should be studied as well. ${ }^{12}$

\footnotetext{
11 In games with incomplete information, transfers may signal a "chicken" attitude of the prey so they may exacerbate the demands of the predator and make war inevitable. We do not discuss whether this effect exists. We just point out that, at least in some cases, there is also a good side of "being chicken" namely that an increase in the wealth of our enemy may make him less aggressive.

12 For instance, the rich country can partially destroy its own resources without transferring them to the poor. This mechanism is less powerful than the one considered here because it affects relative wealth only by making the rich country less rich and not by making the poor country richer. But it may work in cases in which, by whatever reason, the poor could not receive transfers.
} 
We may wonder if the success of transfers to stop war depends heavily on our game form (i.e. the order of stages, what is decided in each stage, etc.). Of course there are circumstances under which transfers are not useful. For instance if, after both players have decided not to attack, one player can secretly raise an army, attack and win the war with no cost, transfers will be useless. But our insight is that transfers may stop a war because the opportunity cost of war for the predator rises. This mechanism is independent of the game form. Consider the following example. Suppose that only player 2 can attack and that war efforts are exogenously given. Thus, the situation after transfers are made is not game-theoretical, but decisiontheoretical. If the attack occurs, player $i=1,2$ looses $C_{i}$ resources. If player 2 attacks he obtains $V_{1}-C_{1}$ from player 1 with probability $p$. In this case player 1 is left with no resources. With probability $1-p$ the attack is repelled and no player takes resources from the other player. Thus the expected utility of war for player 2 is $p\left(V_{1}-C_{1}+V_{2}-C_{2}\right)-(1-p) C_{2}$. Suppose that this number is larger than $V_{2}$, i.e. $p\left(V_{1}-C_{1}+V_{2}-C_{2}\right)-(1-p) C_{2}>V_{2}$, thus player 2 has incentives to attack. Assuming for simplicity that the transfer does not affect neither costs nor the outcome of the conflict, peace can be achieved if there is a transfer $T$ such that the player 2 with this transfer in hand has no incentive to attack, namely, $p\left(V_{1}-C_{1}+V_{2}-C_{2}\right)-(1-p) C_{2} \leqslant V_{2}+T$ and player 1 is better off after the transfer namely $(1-p)\left(V_{1}-C_{1}\right)<V_{1}-T$. The above two inequalities are compatible iff $V_{1}-(1-p)\left(V_{1}-C_{1}\right)>p\left(V_{1}-C_{1}+V_{2}-C_{2}\right)-(1-p) C_{2}-V_{2}$ which is equivalent to $C_{1}+C_{2}+V_{2}(1-p)>0 .{ }^{13}$ Thus, peace is always achieved by the appropriate transfer. Notice that when a costless surprise attack wins the war, $C_{1}=C_{2}=0$ and $p=1$, such transfer does not exist. For a model of surprise attacks see for instance Alesina and Spolaore (2005).

\section{Appendix A}

Lemma 1. Let $k \in[0.5,1)$. Suppose that a peace agreement is feasible with a transfer $\hat{T}$ such that after the transfer both players are unconstrained. Then, a peace agreement is also feasible with a transfer $T^{\prime}<\hat{T}$ such that only player 2 is constrained.

Proof. Since $k \in[0.5,1), \min (1 / 4 k, k)=1 / 4 k$. Thus, the constraints for $T^{\prime}$ are $k /(1+k)^{2} \leqslant\left(V_{2}+T^{\prime}\right) / V<1 / 4 k$. Notice first that $k /(1+k)^{2}<1 / 4 k$ since $k<1$, so $T^{\prime}$ can be chosen between these bounds. Furthermore, since $1 / 4 k \leqslant\left(V_{2}+T^{\prime}\right) / V$ and $\left(V_{2}+T^{\prime}\right) / V<1 / 4 k$, then $T^{\prime}<\hat{T}$ and thus $\left(V_{2}+T^{\prime}\right) / V \leqslant-k V_{2} / V+2 \sqrt{k V_{2} / V}$. We finally show that $T^{\prime}$ can be chosen such that $-k V_{2} / V+\sqrt{k V_{2} / V} \leqslant\left(V_{2}+T^{\prime}\right) / V$. Since $V_{2} / V<1 / 4 k,-k V_{2} / V+\sqrt{k V_{2} / V}<1 / 4 k$, and since $k<1,1 / 4<1 / 4 k$. Thus, choosing $T^{\prime}$ such that $\left(V_{2}+T^{\prime}\right) / V \simeq 1 / 4 k$ will satisfy the desiderata.

Lemma 2. Let $k \in(0,0.5)$. Suppose that a peace agreement is feasible with a transfer $\hat{T}$ such that after the transfer both players are constrained. Then, a peace agreement is also feasible with a transfer $T^{\prime}<\hat{T}$ such that only player 2 is constrained.

Proof. Since $k \in(0,0.5), \min (1 / 4 k, k)=k$. Thus the constraints for $T^{\prime}$ are $k /(1+k)^{2} \leqslant\left(V_{2}+T^{\prime}\right) / V<k$. Notice first that $k /(1+k)^{2}<k$, so $T^{\prime}$ can be chosen between these bounds. Furthermore, since $k<\left(V_{2}+\hat{T}\right) / V$ and $\left(V_{2}+T^{\prime}\right) / V<k, T^{\prime}<\hat{T}$ and thus $\left(V_{2}+T^{\prime}\right) / V \leqslant-k V_{2} / V+2 \sqrt{k V_{2} / V}$. We finally show that $T^{\prime}$ can be chosen such that $-k V_{2} / V+\sqrt{k V_{2} / V} \leqslant$ $\left(V_{2}+T^{\prime}\right) / V$. Since $V_{2} / V \leqslant k<1 / 4 k$, and $-k V_{2} / V+\sqrt{k V_{2} / V}$ is increasing for all $\frac{V_{2}}{V} \in[0,1 / 4 k],-k V_{2} / V+\sqrt{k V_{2} / V} \leqslant$ $-k^{2}+k<k$. Thus, choosing $T^{\prime}$ such that $\left(V_{2}+T^{\prime}\right) / V \simeq k$ will satisfy the desiderata.

Lemma 3. If before the transfer war occurs, $-k V_{2} / V+\sqrt{k V_{2} / V} \leqslant k /(1+k)^{2}$.

Proof. Since war occurs, $V_{2} / V<k /(1+k)^{2}$. The function $-k V_{2} / V+\sqrt{k V_{2} / V}$ is increasing in $V_{2} / V$ in the interval $\left[0, \frac{1}{4 k}\right]$, since $k /(1+k)^{2}<\frac{1}{4 k}$, the maximal value in the relevant interval is reached at $V_{2} / V=k /(1+k)^{2}$. Thus, $-k V_{2} / V+\sqrt{k V_{2} / V} \leqslant k /(1+k)^{2}$.

Lemma 4. Let $k \in(0,1]$. There is a solution $x_{1}(k)$ of equation $k /(1+k)^{2}=-k x+2 \sqrt{x k}$ such that $x_{1}(k) \in\left[0, k /(1+k)^{2}\right)$.

Proof. Let

$$
x_{1}(k)=\frac{\left(4-\frac{2 k}{(1+k)^{2}}\right)-\frac{4}{(1+k)} \sqrt{1+k+k^{2}}}{2 k} .
$$

It is straightforward to see that $x_{1}(k)$ so define is a solution of the equation $k /(1+k)^{2}=-k x+2 \sqrt{x k}$. Suppose that there is $k \in(0,1]$ such that $x_{1}(k)>k /(1+k)^{2}$. Since $x=k /(1+k)^{2}$ is the solution of the equation $k /(1+k)^{2}=-k x+\sqrt{x k}$ and $-k x+\sqrt{x k}$ is increasing in $x \in[0,1 / 4 k], k /(1+k)^{2}<-k x_{1}(k)+\sqrt{x_{1}(k) k}$. But, $-k x_{1}(k)+\sqrt{x_{1}(k) k} \leqslant-k x_{1}(k)+2 \sqrt{x_{1}(k) k}=$ $k /(1+k)^{2}$, which is a contradiction. Therefore, $x_{1}(k) \leqslant k /(1+k)^{2}$.

\footnotetext{
13 Notice that the minimal transfer that stops war, namely $p\left(V_{1}-C_{1}+V_{2}-C_{2}\right)-(1-p) C_{2}-V_{2}$ is always less than $V_{1}$ independently of $V_{1}$ being larger or smaller than $V_{2}$.
} 
Notice first that if $k \in[0.5,1)$, then $1 / 4 k \leqslant k$. By Lemma 3 a peace agreement in this case is feasible if and only if

$$
\frac{k}{(1+k)^{2}}<\min \left(\frac{1}{4 k},-k \frac{V_{2}}{V}+2 \sqrt{\frac{V_{2}}{V} k}\right) \text {. }
$$

Lemma 5. Let $k \in[0.5,1)$. There is a solution $x_{0}(k)$ of equation $1 / 4 k=-k x+2 \sqrt{x k}$ such that $x_{0}(k) \in\left[0, k /(1+k)^{2}\right)$.

Proof. Let

$$
x_{0}(k)=\frac{-0.5+4 k-\sqrt{16 k^{2}-4 k}}{2 k^{2}} .
$$

It is straightforward to see that $x_{0}(k)$ so define is a solution of the equation $1 / 4 k=-k x+2 \sqrt{x k}$. Furthermore, $x_{0}(k)$ is decreasing in $k$ for all $k \in[0.5,1)$. Since $k /(1+k)^{2}$ is increasing in $[0.5,1)$, and $x_{0}(0.5)=0.17157<0.5 /(1+0.5)^{2}=$ 0.22222 , then $x_{0}(k) \in\left[0, k /(1+k)^{2}\right)$.

Lemma 6. Let $k \in[0.5,1)$. Then, $x_{1}(k)<x_{0}(k)$.

Proof. Since $k /(1+k)^{2}<1 / 4 k$ for all $k \in[0.5,1)$ and $-k x+2 \sqrt{x k}$ is increasing for all $x \in\left[0, k /(1+k)^{2}\right)$, it follows that $x_{1}(k)<x_{0}(k)$.

Lemma 7. Let $k \in[0.5,1)$. If $V_{2} / V \geqslant x_{0}(k)$, a peace agreement is feasible.

Proof. Since $-k x+2 \sqrt{x k}$ is increasing for all $x \in\left[0, k /(1+k)^{2}\right)$, if $V_{2} / V \geqslant x_{0}(k)$ then $1 / 4 k \leqslant-k V_{2} / V+2 \sqrt{k V_{2} / V}$. Since $k /(1+k)^{2}<1 / 4 k$, condition (A.2) is satisfied, and therefore, a peace agreement is feasible.

Lemma 8. Let $k \in[0.5,1)$. If $x_{1}(k)<V_{2} / V<x_{0}(k)$, a peace agreement is feasible.

Proof. Since $V_{2} / V<x_{0}(k)$, then $-k V_{2} / V+2 \sqrt{k V_{2} / V}<1 / 4 k$. Since $x_{1}(k)<V_{2} / V$, and $-k x+2 \sqrt{x k}$ is increasing for all $x \in\left[0, k /(1+k)^{2}\right)$, it follows that $k /(1+k)^{2}<-k V_{2} / V+2 \sqrt{k V_{2} / V}$. Thus condition (A.2) is satisfied, and therefore, a peace agreement is feasible.

Lemma 9. Let $k \in[0.5,1)$. If $V_{2} / V \leqslant x_{1}(k)$, there is no possibility of a peace agreement.

Proof. Clearly, if $V_{2} / V \leqslant x_{1}(k)$, then $k /(1+k)^{2} \geqslant-k V_{2} / V+2 \sqrt{k V_{2} / V}$. Since $x_{1}(k)<x_{0}(k)$, it follows that $-k V_{2} / V+$ $2 \sqrt{k V_{2} / V}<1 / 4 k$. Thus, condition (A.2) is never satisfied.

Secondly, notice that if $k \in(0,0.5), k /(1+k)^{2}<k<1 / 4 k$. By Lemma 3 a peace agreement in this case is feasible if and only if

$$
\frac{k}{(1+k)^{2}}<\min \left(k,-k \frac{V_{2}}{V}+2 \sqrt{\frac{V_{2}}{V} k}\right) .
$$

Lemma 10. Let $k \in(0,0.5)$. There is a solution $x_{2}(k)$ of equation $k=-k x+2 \sqrt{x k}$ such that $x_{2}(k) \in\left(0, k /(1+k)^{2}\right)$.

Proof. Let $x_{2}(k)=(2-k-2 \sqrt{1-k}) / k$. It is straightforward to see that $x_{2}(k)$ so defined is a solution of the equation $k=-k x+2 \sqrt{x k}$. Furthermore, $x_{2}(k)$ is increasing in $(0,0.5), \lim _{x \rightarrow 0} x_{2}(0)=0$ which coincides with the value of $k /(1+k)^{2}$ in $k=0$, and $x_{2}(0.5)=3-2 \sqrt{2}<0.5 /(1+0.5)^{2}=2 / 9$. Since $k /(1+k)^{2}$ is also increasing, it follows that $x_{2}(k) \in(0, k /$ $\left.(1+k)^{2}\right)$.

Lemma 11. Let $k \in(0,0.5)$. Then, $x_{1}(k)<x_{2}(k)$.

Proof. Since $k /(1+k)^{2}<k$ for all $k \in(0,0.5)$ and $-k x+2 \sqrt{x k}$ is increasing for all $x \in\left[0, k /(1+k)^{2}\right)$, then $x_{1}(k)<x_{2}(k)$.

Lemma 12. Let $k \in(0,0.5)$. If $V_{2} / V \geqslant x_{2}(k)$, a peace agreement is feasible.

Proof. Since $-k x+2 \sqrt{x k}$ is increasing for all $x \in\left[0, k /(1+k)^{2}\right)$, if $V_{2} / V \geqslant x_{2}(k)$ then $k \leqslant-k V_{2} / V+2 \sqrt{k V_{2} / V}$. Since $k /(1+k)^{2}<k$, condition (A.4) is satisfied, and therefore, a peace agreement is feasible. 
Lemma 13. Let $k \in(0,0.5)$. If $x_{1}(k)<V_{2} / V<x_{2}(k)$, a peace agreement is feasible.

Proof. Since $V_{2} / V<x_{2}(k),-k V_{2} / V+2 \sqrt{k V_{2} / V}<k$. Since $x_{1}(k)<V_{2} / V$, and $-k x+2 \sqrt{x k}$ is increasing for all $x \in$ $\left[0, k /(1+k)^{2}\right)$, then $k /(1+k)^{2}<-k V_{2} / V+2 \sqrt{k V_{2} / V}$. Thus condition (A.4) is satisfied, and therefore, a peace agreement is feasible.

Lemma 14. Let $k \in(0,0.5)$. If $V_{2} / V \leqslant x_{1}(k)$, there is no possibility of a peace agreement.

Proof. Clearly, if $V_{2} / V \leqslant x_{1}(k)$, then $k /(1+k)^{2} \geqslant-k V_{2} / V+2 \sqrt{k V_{2} / V}$. Since $x_{1}(k)<x_{2}(k)$, it follows that $-k V_{2} / V+$ $2 \sqrt{k V_{2} / V}<k$. Thus, condition (A.4) is never satisfied.

Proof of Proposition 3. If $k=1$, notice that it is impossible to be in Case 3.3 or in Case 3.2 after the transfer, so we are left with Case 3.1 as the only possibility for achieving peace. Then, conditions 1,2 , and 3 read $V_{2} / V<\frac{1}{4},-V_{2} / V+\sqrt{V_{2} / V} \leqslant$ $\left(V_{2}+T\right) / V \leqslant-V_{2} / V+2 \sqrt{V_{2} / V}$ and $1 / 4 \leqslant\left(V_{2}+T\right) / V$. It can be easily shown that for $V_{2} / V<1 / 4,-V_{2} / V+\sqrt{V_{2} / V} \leqslant$ $1 / 4$. Thus, the transfer that brings peace exists if and only if $1 / 4<-V_{2} / V+2 \sqrt{V_{2} / V}$, i.e. if and only if $V_{2} / V>x_{1}(1)$, otherwise, is not in the interest of player 1 to make any transfer.

It follows directly from Lemmas 7,8 and 9 that a peace agreement for $k \in[0,5,1)$ is feasible if and only if $V_{2} / V>x_{1}(k)$.

It also follows directly from Lemmas 12,13 and 14 that a peace agreement for $k \in(0,0.5)$ is feasible if and only if $V_{2} / V>x_{1}(k)$.

The minimal transfer needed is such that $k /(1+k)^{2}=\left(V_{2}+\hat{T}\right) / V$. Notice that for such a transfer player 2 is indifferent between war and peace, since for $\hat{T}$ it holds that $V_{2}+\hat{T}=E \pi_{2}^{*}=\sqrt{V\left(V_{2}+\hat{T}\right) k}-k\left(V_{2}+\hat{T}\right)$.

Proof of Proposition 5. Consider the second stage of the game where war would be declared when no transfers are made, but that a transfer $\hat{T}$ such that $V_{2}+\hat{T}=V / 2(1+\gamma)$ has been made. After the transfer, payoff for player 1 in case of peace is given by $V_{1}-\hat{T}=V-V / 2(\gamma+1)$. If we assume that this payoff is less than the payoff in the case of a war with no transfer, then $V<V /(\gamma+1)$, which is impossible. Thus, $\hat{T}$ yields an incentive for peace for both players. It is only left to show that after the transfer, player 1 is not constrained, which amounts to

$$
V_{1}-\hat{T} \geqslant \frac{\gamma V}{2 k(\gamma+1)} \Leftrightarrow V-\frac{V}{2(\gamma+1)} \geqslant \frac{\gamma V}{2 k(\gamma+1)} \Leftrightarrow k \geqslant \frac{\gamma}{2 \gamma+1} .
$$

By Proposition 4, if the relatively poor player had an incentive to go to war before the transfer, $\gamma<k$. But then, $k>\gamma>$ $\gamma /(2 \gamma+1)$, as desired.

Proof of Proposition 6. If $k \simeq 0$ and $\gamma \in(0,1)$ both players are constrained and player 2 has incentives to declare war as we have seen before. The minimal transfer that avoids war is such that player 2 has no incentives to declare war after the transfer. That is, after the transfer, the resources in hands of player 2, say $V_{2}^{\prime}$, should be such that

$$
\frac{V_{2}^{\prime}}{V}=\frac{V_{2}^{\prime \gamma}}{\left(V_{1}^{\prime \gamma}+V_{2}^{\prime \gamma}\right)}(1-k) \simeq \frac{V_{2}^{\prime \gamma}}{\left(V_{1}^{\prime \gamma}+V_{2}^{\prime \gamma}\right)}
$$

The above equation implies that approximately half of the total resources should be in hands of player 2. But, if this is the case, player 1 is worse off after the transfer than with war because

$$
\frac{V_{1}^{\gamma}}{\left(V_{1}^{\gamma}+V_{2}^{\gamma}\right)} V>\frac{1}{2} V \simeq V_{1}^{\prime}
$$

Proof of Proposition 7. Suppose that when player 2 takes an effort $V_{2}$ the best reply of player 1 is interior. Thus, from $\partial E \pi_{1}\left(e_{1}, V_{2}\right)=0$, we obtain that $V_{2}^{\gamma} \gamma\left(V-k\left(e_{1}+V_{2}\right)\right)=\left(e_{1}^{\gamma}+V_{2}^{\gamma}\right) e_{1} k$. Since the left-hand side is decreasing in $e_{1}$ and the right-hand side is increasing in $e_{1}$ the solution, if exists, is unique. When $e_{1}=0$ the left-hand side is larger than the right-hand side. Hence, if when $e_{1}=V_{1}$ the left-hand side is larger than the right-hand side too, the above equation does not have a solution. This happens when

$$
\frac{V_{2}^{\gamma} V}{\left(V_{1}^{\gamma}+V_{2}^{\gamma}\right) V_{1}}>\frac{k}{\gamma(1-k)}
$$

which holds for $k$ close to zero. Thus, the best reply of player 1 is either $e_{1}=0$ or $e_{1}=V_{1}$. Since the former yields $E \pi_{1}=0$ and the latter yields, approximately, $\left(V_{1}^{\gamma} /\left(V_{1}^{\gamma}+V_{2}^{\gamma}\right)\right) V$, the best reply for player 1 is $e_{1}=V_{1}$.

A reasoning identical to the one used with player 1 shows that the optimal reply of player 2 is $e_{2}=V_{2}$. Therefore, payoffs of war are, approximately, 


$$
E \pi_{i} \simeq \frac{V_{i}^{\gamma}}{V_{1}^{\gamma}+V_{2}^{\gamma}} V, \quad i=1,2
$$

Since $\left(V_{2} / V_{1}\right)^{\gamma}$ decreases with $\gamma$, the expected payoff for player 1 increases with $\gamma$ which, together with $\gamma>1$ implies that

$$
\frac{V_{1}^{\gamma}}{V_{1}^{\gamma}+V_{2}^{\gamma}} V>\frac{V_{1}}{V_{1}+V_{2}} V=V_{1}
$$

Thus, player 1 has incentives to declare war.

Since $\left(V_{1} / V_{2}\right)^{\gamma}$ increases with $\gamma$, the expected payoff for player 2 decreases with $\gamma$ which, together with $\gamma>1$ implies that

$$
\frac{V_{2}^{\gamma}}{V_{1}^{\gamma}+V_{2}^{\gamma}} V<\frac{V_{2}}{V_{1}+V_{2}} V=V_{2}
$$

Thus, player 2 never declares war.

The maximal transfer that player 2 is ready to make to player 1 is such that

$$
\frac{V_{2}^{\gamma}}{V_{1}^{\gamma}+V_{2}^{\gamma}} V(1-k)=V_{2}-T
$$

Then, the resources in hand of player 1 after the transfer are such that

$$
V_{1}+T=k V+\frac{V_{1}^{\gamma}}{V_{1}^{\gamma}+V_{2}^{\gamma}} V(1-k)
$$

Let $V_{1}^{\prime}=V_{1}+T$ and $V_{2}^{\prime}=V_{2}-T$. For $k$ sufficiently small,

$$
V_{1}^{\prime} \simeq \frac{V_{1}^{\gamma}}{V_{1}^{\gamma}+V_{2}^{\gamma}} V<\frac{V_{1}^{\prime \gamma}}{V_{1}^{\prime \gamma}+V_{2}^{\prime \gamma}} V
$$

The right-hand side of the above inequality is approximately the expected payoff of player 1 in case of war after the transfer. Thus, the maximal transfer that player 2 is able to make, does not prevent war.

Proof of Proposition 10. Let $\hat{T}$ be such that $k \lambda V=\left(V_{2}-\hat{T}\right)(\lambda-1)$. Let $V_{2}^{\prime}=\left(V_{2}-\hat{T}\right)$, and $V_{1}^{\prime}=V_{1}+\hat{T}$. Because of the definition of the new distribution of resources, after the transfer player 1 has no incentive to declare war (see Proposition 9). What it is not clear is whether he will accept the transfer. So, we have to see that

$$
E \pi_{1}\left(V_{1}, V_{2}\right)=\frac{\lambda V_{1} V(1-k)}{\lambda V_{1}+V_{2}} \leqslant V_{1}^{\prime}=V-V_{2}^{\prime}=V\left(1-\frac{k \lambda}{(\lambda-1)}\right) .
$$

The left-hand side is clearly increasing in $V_{1}$, thus

$$
\frac{\lambda V_{1} V(1-k)}{\lambda V_{1}+V-V_{1}}<\frac{\lambda V_{1}^{\prime} V(1-k)}{\lambda V_{1}^{\prime}+V-V_{1}^{\prime}}=V_{1}^{\prime} .
$$

Finally, let us prove that player 2 is also better off. So we have to compare the payoffs of player 2 at $V_{2}^{\prime}=V k \lambda /(\lambda-1)$ with the payoffs should a war arise. That is, we have to show that

$$
\frac{V_{2}(1-k)}{\lambda V-\lambda V_{2}+V_{2}} \leqslant \frac{k \lambda}{(\lambda-1)}
$$

Notice first that when $\lambda \rightarrow \infty$, the left-hand side tends to zero and the right-hand side tends to $k$. Secondly, when $\lambda \rightarrow 1$, the left-hand side tends to $V_{2}(1-k)$ and the right-hand side tends to $\infty$. Thus, if the inequality were the other way around for some value of $\lambda$, there must be, generically, two positive solutions to the equation $V_{2}(1-k)(\lambda-1)=k \lambda\left(\lambda V-\lambda V_{2}+V_{2}\right)$. It is easy to see that this equation has, at most, one positive root. Thus, there must be a contradiction.

\section{References}

Acemoglu, Daron, 2003. Why not a political Coase theorem? Social conflict, commitment and politics. J. Compar. Econ. 31 (4), 620-652.

Alesina, Alberto, Spolaore, Enrico, 2005. War, peace and the size of countries. J. Public Econ. 89 (7), 1333-1354.

Bester, Helmut, Konrad, Kai A., 2005. Easy targets and the timing of conflict. J. Theoretical Politics 17 (2), $199-215$.

Bueno de Mesquita, Bruce, 1981. The War Trap. Yale University Press.

Bueno de Mesquita, Bruce, Lalman, David, 1992. War and Reason. Yale University Press.

Bueno de Mesquita, Bruce, Smith, Alastair, Siverson, Randolph, Morrow, James, 2003. The Logic of Political Survival. The MIT Press. 
Clark, Derek, Riis, Christian, 1998. Contest success functions: An extension. Econ. Theory 11, 201-204.

Clausewitz, Carl von, 1832. On War. Spanish edition translated by Carlos Fortea. La Esfera de los Libros, Madrid, 2005.

Esteban, Joan, Ray, Debraj, 1999. Conflict and distribution. J. Econ. Theory 87, 379-415.

Evans, James, 1998. Justinian. In: An Online Encyclopedia of Roman Emperors.

Fearon, James, 1995. Rationalist explanations for war. Int. Organ. 49, 379-414.

Garfinkel, Michelle, Skaperdas, Stergios, 2000. Conflict without misperceptions or incomplete information: How the future matters. J. Conflict Resolution 44 (6), 793-807.

Garfinkel, Michelle, Skaperdas, Stergios, 2007. Economics of conflict: An overview. In: Sandler, T., Hartley, K. (Eds.), Handbook of Defense Economics, vol. 2. North-Holland, Amsterdam. Chapter 22.

Gibbons, E., 1776-1788. The decline and fall of Roman empire. Available online from several sources.

Hirshleifer, Jack, 1991. The paradox of power. Econ. Politics 3, 177-200.

Jackson, Matthew, Morelli, Massimo, 2007. Political bias and war. Amer. Econ. Rev. 97 (4), 1353-1373.

Jackson, Matthew, Morelli, Massimo, 2009. Strategic militarization, deterrence and war between nations. Mimeo: Stanford University.

Keegan, John, 1994. A History of Warfare. Vintage Books, New York.

Morrow, James, 2008. Choosing war: State decisions to initiate and end wars and observe the peace after wars. University of Michigan, unpublished.

Nunn, Nathan, 2007. The long-term effects of Africa's Slavetrades. University of British Columbia, July, unpublished.

Nelson, Lynn, 1979. Christian-Muslim relationships in eleventh century Spain. Military Affairs 43 (4), 195-198.

O'Neill, Barry, 1990. A survey of game theory models on peace and war. In: Aumann, R., Hart, S. (Eds.), Handbook of Game Theory. North-Holland.

Perez-Castrillo, David, Verdier, Thierry, 1992. A general analysis of rent-seeking games. Public Choice 73 (3), 335-350.

Piccione, Michele, Rubinstein, Ariel, 2004. The curse of wealth and power. J. Econ. Theory 117, 119-123.

Ponsatí, Clara, 2004. Economic diplomacy. J. Public Econ. Theory 6 (5), 675-691.

Powell, Robert, 1996. Uncertainty, shifting power, and appeasement. Amer. Polit. Sci. Rev. 90 (4), 749-764.

Rajan, G. Raghuram, Zingales, Luigi, 2000. The tyranny of inequality. J. Public Econ. 76, 3. 521-558.

Sánchez-Pagés, Santiago, 2006. On the social efficiency of conflict. Econ. Letters 90 (1), 96-101.

Skaperdas, Stergios, 1992. Cooperation, conflict, and power in the absence of property rights. Amer. Econ. Rev. 82 (4), $720-739$.

Skaperdas, Stergios, 1996. Contest success functions. Econ. Theory 7, 283-290.

Smith, Adam, 1776. An Inquiry into the Nature and Causes of the Wealth of Nations. Methuen and Co., Ltd. Ed. Edwing Cannan.

Smith, Alastair, Stam, Allan, 2004. Bargaining and the nature of war. J. Conflict Resolution 48 (6), 783-813.

Sykes, Bryan, 2006. Saxons Vikings and Celts. W.W. Norton, New York.

Tullock, Gordon, 1980. Efficient rent-seeking. In: Buchanan, J.M., Tollison, R.D., Tullock, G. (Eds.), Towards a Theory of a Rent-Seeking Society. Texas A\&M University Press, pp. 97-112. 